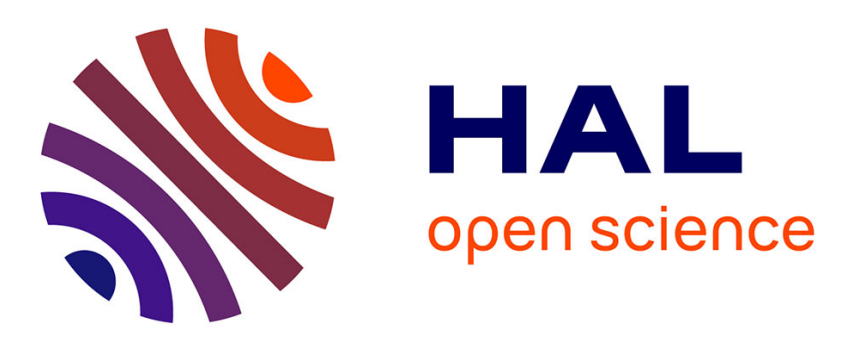

\title{
Overview of microgrippers and design of a micro-manipulation station based on a MMOC microgripper
}

Joël Agnus, Patrick Nectoux, Nicolas Chaillet

\section{- To cite this version:}

Joël Agnus, Patrick Nectoux, Nicolas Chaillet. Overview of microgrippers and design of a micromanipulation station based on a MMOC microgripper. Proceedings of the IEEE International Symposium on Computational Intelligence in Robotics and Automation, CIRA'05., Jun 2005, Espoo, Finland. 7 p. hal-00661471

\section{HAL Id: hal-00661471 \\ https://hal.science/hal-00661471}

Submitted on 14 Feb 2013

HAL is a multi-disciplinary open access archive for the deposit and dissemination of scientific research documents, whether they are published or not. The documents may come from teaching and research institutions in France or abroad, or from public or private research centers.
L'archive ouverte pluridisciplinaire $\mathbf{H A L}$, est destinée au dépôt et à la diffusion de documents scientifiques de niveau recherche, publiés ou non, émanant des établissements d'enseignement et de recherche français ou étrangers, des laboratoires publics ou privés. 


\title{
Overview of Microgrippers and Design of a Micro- manipulation Station Based on a MMOC Microgripper
}

\author{
Joël Agnus, Patrick Nectoux and Nicolas Chaillet \\ Laboratoire d'Automatique de Besançon \\ UMR CNRS 6596 - ENSMM - Université de Franche-Comté \\ 24 rue Alain Savary, 25000 Besançon, France \\ joel.agnus@ens2m.fr_patrick.nectoux@ens2m.frrnicolas.chaillet@ens2m.fr
}

\begin{abstract}
This paper deals with an overview of recent microgrippers. As the end-effectors of micromanipulation systems, microgrippers are crucial point of such systems for their efficiency and their reliability. The performances of current microgrippers are presented and offer a stroke extending from $50 \mu \mathrm{m}$ to approximately $2 \mathrm{~mm}$ and a maximum forces varying from $0,1 \mathrm{mN}$ to $600 \mathrm{mN}$. Then, micromanipulation system based on a piezoelectric microgripper and a SCARA robot is presented.

Index Terms-micromanipulation, microgripper, micro-
\end{abstract} robot, piezoelectric, MOC.

\section{INTRODUCTION}

Pick-and-place tasks are largely widespread operations in the industrial world. These tasks, well controlled for parts of a few millimeters cubes and more, become very delicate when one wishes to handle objects of a few tens to several hundreds of micrometers. At these scales, surface forces become dominating in comparison with volumic forces [1], [2]. If certain classes of objects can be handled by processes which proved a good reliability, in particular vacuum grippers for the positionning of electronic components for instance, manipulators with tightened fingers remain universal, intuitive tools for the user and can address a significant part in the resolution of microhandling problems.

Nowadays, various manufacturers propose micropositionning systems having good characteristics, in particular a submicrometric resolution. On the other hand, relatively few microgrippers are available on the market. We listed a great number of prototypes resulting from laboratories and we still note a strong interest of the scientific community for microgrippers. A justified passion because the field of micromanipulation is far from being dried up and the needs are growing. Indeed, micromanipulation, i.e. handling of objects with dimensions from $1 \mu \mathrm{m}$ to $1 \mathrm{~mm}$, and microassembly concern many domains. Among these fields, we can quote:

- the assembly of rigid micromechanical parts such as microgears, optical lenses, microcomponents for the realization of hybrid circuits;

- the handling of samples for testing or characterizing them. Indeed, the characteristics of microparts carried out by microtechnology processes could be different as their counterparts obtained by more traditional processes in a bulk form. When microtechnic parts are produced, it is then necessary to carry out test samples from the same substrate in order to characterize the material thus elaborated;

- the handling of biological cells for medicine or biotechnologies, which is often carried out in liquid medium;

- the surgery for which certain operations require a precision that the human arm can not reach. It is for example the case for the ophthalmic surgery and the neurosurgery.

Section II gives an overview of microgrippers from research institutes and also from the market. Then, section III presents micromanipulations carried out with a station based on a MMOC Microgripper (Microprehensile Microrobot On Chip) and a SCARA robot.

\section{TWO-FINGERED MICROGRIPPER OVERVIEW}

We list several tens of microgrippers, mainly prototypes resulting from research institutes (see Table I). Some commercial microgrippers are also mentionned which offer is growing up (see Table II). Nevertheless, all of these achievements are rather different the ones from the others and are classified in the following lines according to the principle of actuation used: electrostatic force, thermal effect, magnetic principle, shape memory alloys, fluidic principle, piezoelectric ceramics.

\section{A. Microgrippers from research institutes}

1) Electrostatic microgrippers: all these devices use the Coulomb forces present between two charged plates, subject to a difference of potential. In all cases, the system tends to maximize the capacity. However, there are several manners to generate and to use the electrostatic forces. We listed three types of actuation structures made up of:

- two plane surfaces: [3] proposes a structure made up of two tungsten beams ( $200 \mu \mathrm{m}$ long) offering a stroke of $6 \mu \mathrm{m}$ within bistable operation; [4] uses a structure obtained by deployment of two polysilicon plates designed to integrate the electrostatic actuator, the spring 
TABLE I

CLASSIFICATION OF MICROGRIPPER PROTOTYPES ACCORDING TO THEIR ACTUATION PRINCIPLE AND STRUCTURE

\begin{tabular}{|c|c|c|}
\hline $\begin{array}{l}\text { Actuation } \\
\text { principe }\end{array}$ & Configuration & References \\
\hline \multirow{3}{*}{ Electrostatic } & parallel surfaces & [3] [4] \\
\hline & comb-drive & {$[5]$} \\
\hline & Scratch Drive Actuator & [6] \\
\hline \multirow{3}{*}{$\begin{array}{l}\text { Thermal } \\
\text { Thermal and } \\
\text { magnetic }\end{array}$} & bimorph & [7] [8] [9] \\
\hline & local expansion & {$[10][11]$} \\
\hline & bimorph and Lorentz force & {$[12]$} \\
\hline \multirow{3}{*}{$\begin{array}{l}\text { Shape Memory } \\
\text { Alloy }\end{array}$} & wire or foil & [13] [14] [15] [16] \\
\hline & film coating & [17] \\
\hline & bulck (monolithic) & {$[18][19][20][21]$} \\
\hline \multirow{2}{*}{ Fluidic } & pneumatic & [22] [23] \\
\hline & hydraulic & {$[24]$} \\
\hline \multirow{4}{*}{ piezoelectric } & stack & $\begin{array}{c}{[25][26][27][28]} \\
{[29][11][30]}\end{array}$ \\
\hline & blade & [31] [32] \\
\hline & bimorph & [33] [34] [35] [36] \\
\hline & bulck (monolithic) & {$[37]$} \\
\hline
\end{tabular}

beams and the finger tips of the gripper. The initial gap between the fingers is $100 \mu \mathrm{m}$ and a controller, which introduces a limit voltage of "pull-in" dependent on the current position, allows a residual spacing between the tips of the gripper of $10 \mu \mathrm{m}$ for hundred Volts. The author gives a delay time of $500 \mu$ s to close the gripper and a gripping force of $50 \mu \mathrm{N}$;

- interdigited comb-drives: [5] proposes a polysilicon device. The performances of this microgripper address the handling of very small objects since the amplitude of opening-and-close of the fingers reaches $10 \mu \mathrm{m}$ and generates a force of $104 \mathrm{nN}$ at $50 \mathrm{~V}$;

- scratch drive actuators (SDA): for instance, sixteen SDA elementary actuators equip the polysilicon microgripper in [6]. They are able to move $50 \mu$ and to generate $800 \mu \mathrm{m}$ at the gripper's tip.

2) Thermal microgrippers: the microgrippers actuated by this principle use a dissymmetry which we can be dissociate in two categories:

- a dissymmetry relating to the thermal properties of two materials: in other words, this principle consists of a bimorph effect of a bi-material to obtain a deflection at the end of two beams which composed the microgripper. The heating process is usually obtained by Joule effect using a current through the structure. Ref. [7], [8] and [9] describe microfabricated Si-Al bimophs.

- a difference of temperature, therefore a dissymmetry of dilation, between two areas of a unique material: this principle, used in [10] and [11], consists to heat up a part of the material to obtain a lateral bending of a compliant structure. The heating is also obtained by Joule effect through the conductive material but, in this case, it is the dimensions (shrinking of a local part) that impose the electrical resistance, therefore the dissipated power and then a higher local temperature. Some achievements were made by laser cutting [10] or electro-discharge machining (EDM) [11].

The performances in term of deflection vary from $120 \mu \mathrm{m}$ for [11] to $800 \mu \mathrm{m}$ for [9] by the means of a serial configuration. Maximum force available at the end of grippers largely varies from $15 \mu \mathrm{N}$ for a gripper based on bimophs [7] and can reach $5 \mathrm{mN}$ for a gripper with localized thermal expansion [11]. Concerning the dynamics of these grippers, [7] gives an opening and closing time of $60 \mathrm{~ms}$ and [11] gives an opening time of $160 \mathrm{~ms}$ and $100 \mathrm{~ms}$ for closing.

3) Thermal and magnetic microgripper: The microgripper described in [12] is interesting because of its dual actuation principle. Indeed, it is not only actuated by a thermal bimorph but also by a Lorentz force. As it is necessary to feed a current to heat the bimorph, the author uses this current which, in the presence of an adequate magnetic field, amplifies the deflection by an additional Lorentz force acts on the frame of the finger.

4) SMA actuated microgrippers: shape memory alloys (SMA) are materials which, after permanent deformation at low temperature, return to their initial form by heating. The SMA is able to generate a mechanical work and thus to move a load during the movement to its initial form. Based on this principle, three different kind of structures can be found:

- grippers made up of a compliant structure: these grippers use a constrained SMA actuator to generate a mechanical work in order to deform the structure. The latter can be out of steel [13], plastic [14] or silicon [17], [22], [16].

Ref. [22] proposes a four-link structure allowing a parallel movement of the fingers. The actuators are usually Ni-Ti wires, except the realization of [17] for which the actuators are thin film of $\mathrm{Ni}-\mathrm{Ti}-\mathrm{Cu}$ alloy. The principle generally exploited to heat up the SMA is Joule effect caused by an electrical current directly through the conductive alloy.

The stroke of these microgrippers starts from $110 \mu \mathrm{m}$ for the smallest one [17], and can reach 2,5 $\mathrm{mm}$ for the largest one [13]. The generated forces are of a few tens of milli-Newton: more precisely, $20 \mathrm{mN}$ for [22] and $40 \mathrm{mN}$ for [17]. These grippers, based on a thermal phase transformation, are rather slow: [14] gives a time of $1,75 \mathrm{~s}$ to pick an object and 4,5 s to place it; [15] points out an open-and-close time of $1 \mathrm{~s}$. - monolithic grippers: "monolithic" because they integrate the mechanical structure, actuators, flexible joints and finger tips in the same SMA material. 
A gripper based on a double memory effect is presented by [19]. The open-and-close amplitude of the gripper reaches $150 \mu \mathrm{m}$. The same author also proposes a monolithic gripper made up of an actuator locally heated and a return spring. An originality of this device is its heating mode which is obtained by a laser beam pointed on the zone of actuation.

Concerning the manufacture techniques of these monolithic grippers, a technique usually used consists in cutting out the structure by EDM in fine Ni-Ti alloy plates.

- compliant structure actuated in an antagonistic way by SMA: antagonistic structures are proposed by [18] and [20]. These structures are also called "differential" or "push-pull": an actuator is used for closing the fingers and a second for the opening. The actuators use the one-way memory effect material and the flexible joints of the structure exploit the super-elasticity of shape memory alloys, which has an apparent elastic strain much more important than metals and have a better stability in time than polymers (in particular concerning the creep). This type of differential structure also has the advantage of accelerating the openand-close time: it is of $0,5 \mathrm{~s}$ for [18] and $332 \mathrm{~ms}$ for [20] (i.e. $32 \mathrm{~ms}$ for the opening and $300 \mathrm{~ms}$ for closing, which corresponds to the cooling phase).

Ref. [21] presents a monolithic and antagonistic prototype of microgripper founded on a localised shape memory effect. The latter is obtained by an adequate heat treatment (by laser) of a zone which one wishes to make active. Thus, an electrical current undergoes a higher temperature in the whole structure but only the treated and pre-stressed zone tends to return to its memorized form and generates a force useful for the movement of the structure.

5) Fluidic microgrippers: these grippers exploit the pressure of a fluid to generate the deformation of flexible parts which allows the opening and the closing of the fingers. This actuation principle which gives a great density of energy, makes possible to consider large deformations and important forces. We classify the prototypes according to the nature of the fluid used, a gas or a liquid that conduct to:

- pneumatic grippers: in the presented example, the pressurized gas is the air. [23] uses a conventional piston to actuate a deformable four-links structure ensuring parallel open-and-close of the fingers. The mechanism, made out of aluminium, is machined by conventional techniques. This device allows a stroke of $1200 \mu \mathrm{m}$ for a pressure of $1 \mathrm{Bar}$ and a gripping force of $1400 \mathrm{mN}$ for 2 Bar.

Ref. [15] presents a monolithic push-pull configuration microgripper made up of two pistons, one for the opening and the other for closing, and of a flexible four-links structure to amplify the parallel movements of the fingers. All these elements are made by microfabrication either in silicon by Reactive Ion Etching (RIE) or in a resin (SU8) by a UV Deep Lithography process. This gripper offers stroke of $600 \mu \mathrm{m}$ and a blocking force of $10 \mathrm{mN}$ for a pressure of $120 \mathrm{mBar}$. The dynamic behavior is quite good since the authors point out an amplitude of the finger motions of $500 \mu \mathrm{m}$ at a frequency of $150 \mathrm{~Hz}$.

- hydraulic grippers: [24] presents a prototype using an hydraulic principle with mercury as the fluid. The displacement of the piston is generated in this case by a rise in temperature of the fluid in a deformable chamber. The heating is obtained by the mean of a laser source on an interface in contact with the mercury fluid. The actuator thus made up deforms a final acrylic resin body.

6) Piezoelectric microgrippers: the abundant litterature dealing with piezoelectric microgrippers attests that piezoelectricity is one of the most used actuation principle. Indeed, piezoelectricity offers considerable advantages: a great speed and overall a high resolution. Very early in comparison with the needs in micromanipulation, we can quote the patent described in [38] who proposes in 1986 a structure with two fingers made up of piezoelectric polymer bimophs. The main existing prototypes were classified in three categories, according to their structure of actuation:

- grippers with compliant structure deformed by a piezoelectric actuator: the majority of the authors use commercial piezoelectric stack [25], [26], [31], [29], [27], [30]. Ref. [32] and [11] exploit transverse strains of a piezoelectric blade. These strains are then amplified, typically by a coefficient of 20 up to 50 , in order to obtain significant displacements at the end of the finger tips of a few tens of micrometers to several hundreds of micrometers. The microgripper described in [11] offers a stroke of $60 \mu \mathrm{m}$ whereas the prototypes given in [26] and [30] reach the millimetre of excursion.

Whereas the deformations are amplified, the gripping forces are largely reduced compared to the force generated by the actuator. The range of the gripping force varies from $8 \mathrm{mN}$ for [25] to $600 \mathrm{mN}$ for [29], which remains sufficient to handle submillimeter objects.

The amplification systems are often carried out in metallic materials ( $\mathrm{Ti}, \mathrm{Al}, \mathrm{Cu}$, etc.) but can also be out of glass [31] or silicon [32]. An original compliant structure with variable stiffness by actuating a more rigid flexible joint is proposed in [32]. More traditional, the gripper described in [30] uses a compliant structure equiped with a four-link mechanism which allows a parallel open-and-close.

The fabrication techniques are as varied as used materials: the structures either are cut out in plates by conventional techniques, laser machining and EDM, or produced by electroforming [28]; glass is photo- 
structured and silicon is machined by microtechnology techniques.

- grippers made up of piezoelectric bimorphs: their operating principle is based on the deformation of two beams, mechanically interdependent one of the other, fed by electric fields so that a first blade contracts whereas the other extends thus causing an deflection from the beam.

For the fabrication of these grippers, [34] and [35] use commercial piezoelectric bimophs on which they add steel-stainless finger tips. The gripper of [36] is equipped with two PZT/brass bimophs whose end of the beams play the part of finger tips. With regard to the performances, the grippers of [34] and [35] respectively reach $400 \mu \mathrm{m}$ for a voltage of only $30 \mathrm{~V}$ and $600 \mu \mathrm{m}$ with $50 \mathrm{~V}$. Lastly, these grippers have a low rigidity but can generate a force of $20 \mathrm{mN}$.

- monolithic microgrippers with localized deformations: in this category we can quote the original realization given in [37], the only one with being completely monolithic among the piezoelectric microgripper. Indeed, it integrates the functions of actuation, amplification and finger tips, the whole carried out in a massive piezoelectric ceramics plate (typically with 0.5 to $1 \mathrm{~mm}$ in thickness). Its operating principle is the following: distributed electrodes on each face of ceramics are supplied to extend and contract locally a flexible structure by the means of elastic hinges. The structure is studied to obtain a substantial amplification of the movement of the fingers.

Concerning its characteristics, its rigid structure makes it possible to obtain forces of $100 \mathrm{mN}$ and the maximum excursion of the fingers of $36 \mu \mathrm{m}$.

\section{B. Commercial microgrippers}

Whereas many achievements of microgrippers result from research institutes, one can note that there is not a very abundant commercial offer. Table II gives a non-exhaustive list of the microgrippers we found on the market.

Among the physical principles used, piezoelectricity obtains a large score with four specimens out of eight:

- PiezoSystem Jena proposes a compliant structure actuated by a piezo stack;

- the gripper principle sold by Kleindiek Nanotechnik and Klocke Nanotechnik consists of contact interaction for coarse movements and of a linear deformation for fine movements. There is a difference between these two achievements: the first manufacturer uses in his applications actuators based on rotary motors and the second on linear motors;

- finally, the gripper "MG-1000" proposed by Preiser Scientific exploits the American patent $\mathrm{n}^{\circ}$ US 4610475 [38] which describes a gripper made up of two piezoelectric polymer bimorphs.
TABLE II

COMMERCIAL MICROGRIPPERS

\begin{tabular}{|c|c|c|}
\hline $\begin{array}{l}\text { Actuation } \\
\text { principe }\end{array}$ & Configuration & $\begin{array}{l}\text { Firm (country) } \\
\text { Reference }\end{array}$ \\
\hline \multirow[b]{2}{*}{ thermal } & \multirow{2}{*}{$\begin{array}{c}\text { local expansion } \\
\text { of Si compliant } \\
\text { struture }\end{array}$} & MEMS PI (D) \\
\hline & & $\begin{array}{c}\text { Zyvex (USA) } \\
\text { "Bent Beam Gripper" }\end{array}$ \\
\hline \multirow[t]{2}{*}{ magnetic } & DC micromotor & $\begin{array}{c}\text { Preiser Scientific (USA) } \\
\text { "MG-2" }\end{array}$ \\
\hline & sync. micromotor & Bartels Microtechnik (D) \\
\hline \multirow{4}{*}{ piezoelectric } & bimorph & $\begin{array}{c}\text { Preiser Scientific (USA) } \\
\text { "MG-1000", }\end{array}$ \\
\hline & stack & $\begin{array}{l}\text { PiezoSystem Jena (D) } \\
\text { "S-805-00" }\end{array}$ \\
\hline & \multirow{2}{*}{$\begin{array}{c}\text { "stick-slip" } \\
\text { and } \\
\text { linear } \\
\text { deformation }\end{array}$} & $\begin{array}{c}\text { Kleindiek Nanotechnik (D) } \\
\text { "Omega Gripper" }\end{array}$ \\
\hline & & $\begin{array}{l}\text { Klocke Nanotechnik (D) } \\
\text { "NMG-S Planar Gripper" }\end{array}$ \\
\hline
\end{tabular}

The grippers made by the MEMS Precision Instrument company use the thermal expansion to actuate a compliant structure made in polysilicium or crystalline silicon. These microgrippers, very compact, offer a stroke of $35 \mu \mathrm{m}$ and also have a quite large choice of finger tips.

Two more traditional microgrippers use electromagnetic motors. These two products are different by the use of DC motors (and encoders) for gripper "MG-2" from Preiser Scientific whereas Bartel integrates a synchronous micromotor. In both cases, the rotational movement is converted into a linear movement to deform the flexible structure of the gripper.

\section{Conclusion of the overview}

In conclusion, let us compare the performances of the microgrippers with two tightened fingers previously presented. The figure 1 locates all the grippers for which strokes and maximum gripping forces are known. With the exception of two electrostatic grippers, we note that essential offer is located for ranges of maximum stroke extending from $50 \mu \mathrm{m}$ to approximately $2 \mathrm{~mm}$ and the maximum gripping forces varying from $0,1 \mathrm{mN}$ to $600 \mathrm{mN}$.

It is not necessary to oppose a category of microgrippers to another. Each structure, each principle of actuation have advantages in a given configuration. However, we note that the majority of the presented microgrippers offer one degree of freedom, namely open/close motion of the fingers or, in the best case, two degrees of freedom when the two fingers are controlled independently. This type of grippers allow to grip, to hold and to release an object. The displacement of the gripper in the workspace is usually ensured by the degrees of freedom of the robot. It then seems interesting to extend the basic functionalities of a microgripper (grip, hold and release) towards new functionalities like the orientation of an object between the finger tips of the gripper. 


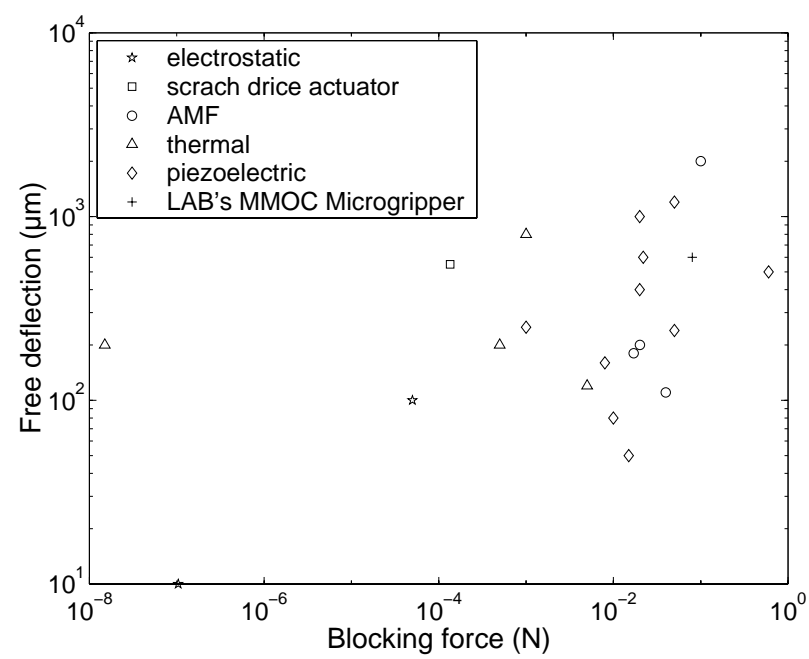

Fig. 1. Performances comparison of several microgrippers.

\section{A MICROMANIPULATION SYSTEM}

\section{A. The four DOF MMOC microgripper}

The MMOC prototype developed at $L A B$ is encapsulated in a compact case. On Fig. 2, the actuators - two piezoelectric bimorphs whose dimensions are $13 \mathrm{~mm}$ long, 1 $\mathrm{mm}$ wide and $0.4 \mathrm{~mm}$ thick - are integrated in a LEMO ${ }^{\circledR}$ connector - $43 \mathrm{~mm}$ long and $12 \mathrm{~mm}$ in diameter - from which emerges the useful parts, i.e. the finger tips - 12 $\mathrm{mm}$ long and $0.2 \mathrm{~mm}$ thick - that are in contact with the manipulated objects.

The performances of such a microgripper (MMOC) are the following:

- the measured strokes of open/close motions and up/down motions are respectively $320 \mu \mathrm{m}$ and $400 \mu \mathrm{m}$ for $100 \mathrm{~V}$;

- the estimated blocking forces on each end-effectors tips are $55 \mathrm{mN}$ in gripping (open/close) and $10 \mathrm{mN}$ in insertion (up/down) for $100 \mathrm{~V}$. These estimations were obtained using a finite element modelling;

- the measured resonance frequencies are $1070 \mathrm{~Hz}$ for gripping motion and $450 \mathrm{~Hz}$ for up-and-down motion.

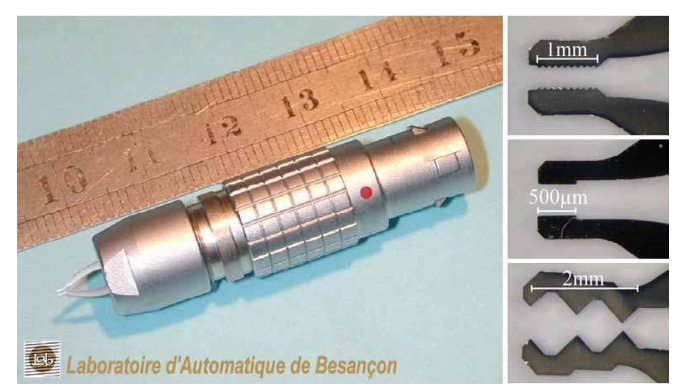

Fig. 2. MMOC Microgripper (left) and finger tips (right).

The geometry of the finger tips can be adapted to the shape of the objects to manipulate, and their material to the required application. The left part of Fig. 2 presents several of those finger tips, made of Nickel, obtained with LIGA machining. A micro-tools changer has also been developed in order to automatically change the finger tips using the same actuator [39].

In summary, the important features of this new microgripper are the number of mobilities, the easy adaptation of the finger tips to the need, the easy plug-and-remove using a standard packaging, and then the easy integration in systems such as a manipulation station. Our microgripper is compared to the overview in Fig. 1.

\section{B. The RP-1AH industrial Robot}

The RP-1AH is an ultra compact SCARA robot with a deforming parallelogram architecture (see Fig. 3). The main specifications are as follow:

- a repeatability of $\pm 5 \mu \mathrm{m}$ in $\mathrm{X}$ and $\mathrm{Y}$ direction, $\pm 10 \mu \mathrm{m}$ in $\mathrm{Z}$ direction and $\pm 0.02^{\circ}$ in $\theta$ axis;

- a high speed operation: a cycle time of 0,28 s (100 mm per $25 \mathrm{~mm}$ );

- a motion range of $150 \mathrm{~mm}$ in width (B), $105 \mathrm{~mm}$ in depth (A) and $30 \mathrm{~mm}$ in height (E). This area is equivalent to A5 size.

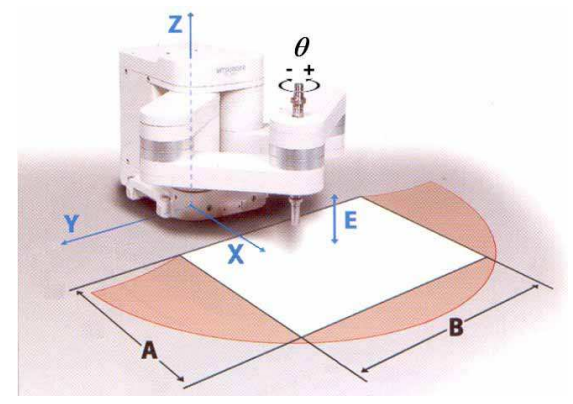

Fig. 3. The RP-1Ah from Mitsubishi.

\section{The micromanipulation station}

The hardware of this station (Fig. 4) is composed of:

- an industrial RP-1AH robot;

- the MMOC gripper with its high voltage interface;

- a PC computer equipped with a National Instruments card (PCI-6733) to drive the microgripper, and with a serial RS-232C port to communicate with the robot;

- several compliant tables giving secure workspaces to avoid damages of the microgripper;

- vision systems based on two cameras (above and side view) with a video monitor which allows a visual feedback.

The software architecture is based on two master-slave applications. The slave program running on the robot controller waits for commands transmitted from the master application. The latter, developed using Labview ${ }^{\circledR} 7.1$ NI, transmits informations required by the robot controller and the microgripper and offers to the operator the following functionnalities: 
- the calibration of the station, carried out only once, allows an easier programming of the robot trajectories and prevent collisions between the microgripper and its environment. To carry out that, two stages are necessary: to determine the tool transform related to the microgripper and to determine the compliant table reference frames.

- the teleoperated micromanipulation: this operating mode allows the operator, via the keyboard and a graphical interface, to control incremental displacements of the robot, in translation according to its xyz axes and rotation $\theta$ around $z$ axis, as well as the microgripper, in open-and-close and up-and-down of the fingers.

- the automatic positionning of objects: this mode allows, once an object is picked by the microgripper, to position it in an automatic way.

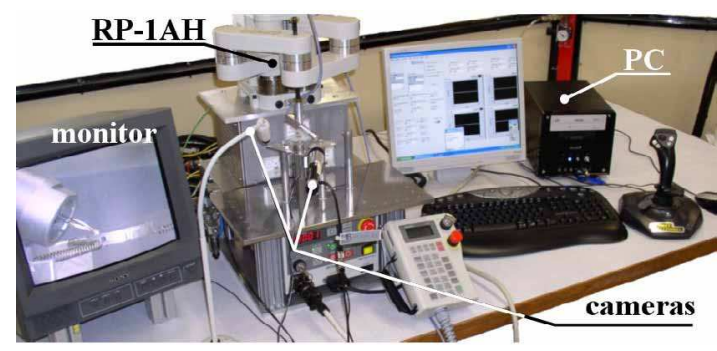

Fig. 4. The micromanipulation station.

\section{D. micromanipulation experiments}

We have used the micromanipulation station to achieve a complete calibration setup in order to perform teleoperated micromanipulations and automatic placements of submillimetric objects. All the experiments reported in these columns concern the micromanipulation of cubic microparts that measure 100 to $700 \mu \mathrm{m}$ in side. Some pictures, extracted from a video sequence, illustrate the functionnalities of the micromanipulation station (see Fig. 5 and 6).

First, the left picture of Fig. 5 shows the axis calibration of a compliant table. The procedure consists to determine the lower vertical limit $z_{0}$ reached when the operator detects, by the means of lateral vision, a soft contact on the table with the finger tips of the gripper. This value is thus stored in the robot interface which manage as a new limit to avoid collisions.

The right picture illustrates the acquisition procedure to determine the tool transform. For each acquisition, the reference point, materialized by the center of a sharp needle, must be located at the center of the finger tips of the gripper. Three different robot locations are needed to compute the tool transform. Once this calibration transferred to the robot interface, the displacement and the rotation are referred to the end of the tool, i.e. the middle end of the finger tips for our MMOC microgripper.


Fig. 5. axis calibration of a compliant table and tool transform calibration.

The automatic mode is illustrated on Fig. 6. Starting from the top-left picture, i.e. a cube is already selected and hold between the finger tips of the gripper, the robot automatically goes to the second working table to place the object at the first programmed position. It comes back to allow the user the selection of an other cube and to place the object to the second programmed position. Then, the procedure can be repeated until filling up the sequence that consist to perform, here, a circular placement on the table as shown on the last picture.


Fig. 6. Teleoperated selection of cubes to perform an automated circular placement of these micro-objects.

\section{CONCLUSION}

While the end-effectors are a crucial point of micromanipulation systems, the present overview show the great interest to solve micromanipulation problems using twofingered microgrippers with various approaches and actuation principles in order to propose efficient and reliable tools. We presented also a four DOF microgripper installed on a SCARA robot to obtain a semi-automatic micromanipulation station. Teleoperated micromanipulations and automatic positioning tasks were successfully carried out. In the future, in order to have a fully automatic micromanipulation station we need to implement vision processing for pattern and objects recognition and force sensing to avoid damages of the handled micro-objects and of the finger tips. For that, the resolution, the repeatability and the accuracy of the global system have to be finely measured. The integration of a micro-tool changer would make the station more flexible. 


\section{REFERENCES}

[1] Q. Zhou, B. Chang, and H. N. Koivo, "Ambiant environmental effects in micro/nano handling," in Proceedings of International Workshop on Micro Factory, 2004, pp. 146-151.

[2] F. Dionnet, D. Haliyo, and S. Régnier, "Autonomous micromanipulation using a new strategy of accurate release by rolling," in Proceedings of IEEE International Conference on Robotics and Automation, New Orleans - USA, April 2004, pp. 5019-5024.

[3] N. C. MacDonald, L. Y. Chen, J. J. Yao, L. Zhang, J. A. McMillan, and D. C. Thomas, "Selective chemical vapor deposition of tungsten for micromechanical structures," Journal of Sensors and Actuators, pp. 123-133, 1989.

[4] P. B. Chu and S. J. Pister, "Analysis of closed-loop control of parall-plate electrostatic microgripper," in Proceedings of IEEE International Conference On Robotics and Automation, vol. 1, San Diego, May 1994, pp. 820-825.

[5] C. J. Kim, A. P. Pisano, and R. Muller, "Overhung electrostatic microgripper,' in TRANSDUCERS'91 - International Conference on Solid State Sensors and Actuators, 1991, pp. 610-613.

[6] O. Millet, P. Bernardoni, S. Régnier, P. Bidaud, D. Collard, and L. Buchaillot, "Micro gripper driven by sdas coupled to an amplification mechanism," 2003.

[7] W. H. Chu and M. Mehregany, "Microfabicated tweezers with large gripping force and a large range motion," in Proceedings of IEEE Solid State Sensor ans Actuator Workshop, Hilton Head, June 13-16 1994, pp. 107-110.

[8] G. Greitmann and R. Buser, "A micromachined gripper with force feedback," in International Symposium on Microsystems, Intelligent Materials and Robots, Sendai - Japan, September 27-29 1995, pp. 75-78.

[9] G.Greitmann and R. Buser, "A tactile microgripper for application in microrobotics," in Proceedings of SPIE, vol. 2906, 1996, pp. 02-12.

[10] P. Lerch, C. K. Slimane, B. Romanowicz, and P. Renaud, "Modelization and characterization of asymmetrical thermal micro-actuactors,' Journal of Micromechanics and Microengineering, no. 6, pp. 134$137,1996$.

[11] H. Du, C. Su, M. Lim, and W. Jin, "A micromachined thermallydriven gripper : a numerical and experimental study," Journal of Smart Materials and Structures, no. 8, pp. 616-622, 1999.

[12] Y. Suzuki, "Flexible microgripper and its application to micromeasurement of mechanical and thermal properties," pp. 406-411, 1996.

[13] R. A. Russell, "A robotic system for performing sub-millimetre grasping and manipulation tasks," Journal of Robotics and Autonomous Systems, no. 13, pp. 209-218, 1994.

[14] M. MacKenzie, N. An, M. Giere, J. Stori, and P. Wright, "Experiences with shape memory alloy : robot grippers for sub-millimeter hard disk drive and components," vol. 2906, 1996, pp. 25-35.

[15] S. Bütefisch, V. Seidemann, and S. Büttgenbach, "A new micro pneumatic actuator for micromechanical systems," in Proc. of 11th International Conference on Solid-State Sensor and Actuators Transducers'01, Germany, June 10-14 2001, pp. 722-725.

[16] J. Hoche, S. Büttgenbach, R. Pittschellis, and J. Hesselbach, "Silicon microgripper for microassembly realized by photolithography and fast anisotropic silicon etching," in SPIE - Conference on Microrobotics and Micromanipulation, vol. 3519, Boston - USA, November 1998, pp. 13-21.

[17] A. P. Lee, D. R. Ciarlo, and P. A. Krulevitch, "A practical microgripper by fine alignment - eutetic bonding and sma actuation," Journal of Sensors and Actuators, vol. 54, no. 1-3, pp. 755-759, 1996.

[18] J. Hesselbach, R. Pittschellis, E. Hornbogen, and M. Mertmann, "Shape memory alloys for use in miniature grippers," in 2nd International Conference on Shape Memory and Superelastic Technologies, USA, 1997, pp. 251-256.

[19] Y. Bellouard, R. Clavel, R. Gotthardt, J. Bidaux, and T. Sidler, "A new concept of monolithic shape memory alloy micro-devices used in micro-robotics," in ACTUATOR 1998 - 6th International Conference on New Actuators, Bremen - Germany, June 17-19 1998, pp. 499-502.

[20] M. Kohl, E. Just, W. Pfleging, and S. Miyazaki, "Sma microgripper with intergrated antagonism," Journal of Sensors and Actuators, no. 83 , pp. $208-213,2000$.
[21] H. Zhang, Y. Bellouard, T. Sidler, E. Burdet, A.-N. Poo, and R. Clavel, "A monolithic shape memory alloy microgripper for 3-d assembly of tissue engineering scaffolds," in Proceedings of SPIE Microrobotics and Microassembly III, vol. 4568, Newton - USA, October 29-30 2001, pp. 50-60.

[22] S. Bütefisch, G. Pokar, S. Büttgenbach, and J. Hesselbach, "A new sma actuated miniature silicon gripper for micro assembly," in ACTUATOR 2000 - 7th International Conference on New Actuators, Bremen - Germany, June 19-21 2000, pp. 334-337.

[23] J. Schlick and D. Zühlke, "Design and application of a gripper for microparts using flexure hinges and pneumatic actuation," in Proceedings of SPIE Microrobotics and Microassembly III, vol. 4568, Newton - USA, October 29-30 2001, pp. 1-11.

[24] W. Nogimori, K. Irisa, M. Ando, and Y. Naruse, "A laser-powered micro-gripper," in Proceedings of IEEE, 1997, pp. 267-271.

[25] Y. Ando, "Microgrippers," Journal of Robotics and Mechatronics, vol. 2, no. 3, pp. 214-216, 1992.

[26] G. Thornell, M. Bexell, J.-A. Schweitz, and S. Johansson, "The design and fabrication of a gripping tool for micromanipulation," in 8th International Conference on Solid State Sensors ans Actuators, Stockholm - Sweden, June 25-29 1995, pp. 388-391.

[27] A. Menciassi, M. Carrozza, C. Ristori, V. Rossi, G. Tiezzi, and P. Dario, "Microgrippers with piezoelectric actuators for a micromanipulation workstation," in 2nd Italian Conference on Sensors and Microsystems. Artificial and Natural Perception, 1997, pp. 333-337.

[28] M. Carrozza, P. Dario, A. Menciassi, and A. Fenu, "Manipulating biological and mechanical micro-objects using liga-microfabricated end-effectors," in IEEE International Conference on Robotics and Automation, Leuven - Belgium, May 1998, pp. 1811-1816.

[29] M. Goldfarb and N. Celanovic, "A flexure-based gripper for smallscale manipulation," Journal of Robotica, vol. 17, pp. 181-187, 1999.

[30] U. Gengenbach, A. Hofmann, F. Engelhardt, R. Scharnowell, and B. Köhler, "The microgripper construction kit," in Proceedings of SPIE Microrobotics and Microassembly III, vol. 4568, Newton USA, October 29-30 2001, pp. 24-31.

[31] R. Salim, H. Wurmus, A. Harnisch, and D. Hülsenberg, "Microgrippers created in microstructurable glass," in International Conference on High Aspect Ratio Microstructure Technology - HARMST'97, July 1997, pp. 32-34.

[32] R. Salim and H. Wurmus, "Multi gearing compliant mechanims for piezoelectric actuated microgrippers," in Actuator 98, 6th International Conference on New Actuators, Bremen - Germany, June 17-19 1998, pp. 186-188.

[33] Y. Umetani, "Principle of a piezo-electric micro manipulator with tactile sensibility," in 8th ISIR, vol. 1, 1978, pp. 406-413.

[34] H. Seki, "Modeling and impedance control of a piezoelectric bimorph microgripper," in IEEE/RSJ International Conference on Intelligent Robots ans Systems, Raleigh, July 7-10 1992, pp. 958965.

[35] S. Chonan, Z. Jiang, and M. Koseki, "Soft-handling gripper driven by piezoceramic bimorph strips," Journal of Smart Materials and Structures, no. 5, pp. 407-414, 1996.

[36] Y. Haddab, N. Chaillet, and A. Bourjault, "A microgripper using smart piezoelectric actuators," in Proceedings of IEEE/RSJ International Conference on Intelligent Robot and Systems, Takamatsu Japan, 2000.

[37] J.-M. Breguet, S. Henein, R. Mericio, and R. Clavel, "Monolithic piezoceramic flexible struture for micromanipulation," in 9th International Precision Engineering Seminar 4th International Conference on Ultraprecision in Manufacturing Engineering, Braunschweig - Germany, 1997, pp. 397-400.

[38] D. Heiserman, "Piezoelectric polymer micromanipulator," in United State Patent, brevet n US 4,610,475, 3 septembre 1986.

[39] C. Clévy, A. Hubert, and N. Chaillet, "A new micro-tools exchange principle for micromanipulation," in Proceedings of International Conference on Intelligent Robot and Systems (IROS), Sendai - Japan, September 28-Ocotober 2 2004, pp. 230-235. 